Send your letters to the Editor,

British Dental Journal,

64 Wimpole Street

London

W1G 8YS

E-mail bdj@bda.org

Priority will be given to letters less than 500 words long.

Authors must sign the letter, which

may be edited for reasons of space.

\section{HARMONIOUS PROPORTION}

Sir, I would like to contribute to the discussion by E. I. Levin, Aesthetic proportions (BDJ 2008; 204: 419-420) about the golden proportion.

When we deal with distorted position or width of the front teeth (for example, lost contact points as a result of caries, spacing or overcrowding) it is fundamentally important to restore the correct correlation of teeth with each other. There is no doubt that the correlation of central incisors to lateral incisors is judged by a human eye as harmonious when it is the golden proportion.

This principle is widely used in dentistry. However, its practical application is rather complicated and often leads to mistakes in calculation. This is due, first, to the fact that the principle of the golden proportion must be applied by dentists when looking at teeth face on. In reality, however, front teeth are located in an arc, which does not let us ascertain the real width of the incisors using a Golden Mean Gauge on photographs. Second, a mistake of $0.5 \mathrm{~mm}$ has a dramatic effect because it leads to visible disproportions of the front teeth correlations. Furthermore, a doctor does not have an opportunity to control the width and the correlation of the teeth in the process of performing a direct restoration with composite.

The problem can be solved using the method by S. V. Radlinskiy, who empirically ascertained the true ratio of central and lateral incisors in the dental arc, thus giving the golden proportion with a face on look.

The upper front teeth coefficients:

Lateral incisors - 1

Central incisors - 1.3 (optimum);

1.5 (maximum), 1.1 (minimum).
The formula of the dental arc:

$X=L / K$

$\mathrm{X}$ - the width of the lateral incisor

$\mathrm{L}$ - the length of the front part of the dental arc

$\mathrm{K}=1+1+1.3+1.3=4.6-$ the sum of the coefficients.

The calculations start from measuring the length of the front part of the dental arc (L). The actual length of each tooth need not be measured: what is relevant is the length of the dental arc. The reference points are any definite spots: contact point, remaining edge of the tooth or the root.

The choice of the reference points for the length of the front part of the dental arc is of great importance. In cases when the contact points of the canines are decayed or the cuspids are at different distances from the central line, one must first define the reference points, for example by restoring the cuspids' contact points.

Once we know the length of the front part of the dental arc (L) it is possible to calculate the width of the lateral incisor (X) and so the width of the central incisor equals $1.3 \mathrm{x}$ ' $\mathrm{X}$ '.

The beauty of this method is that it permits the creation of a restoration plan, controls the width of the incisors during the restoration, and yields excellent predictable results for your patients.

$$
\begin{array}{r}
\text { A. Astakhov } \\
\text { By post } \\
\text { DOI: } 10.1038 / \text { sj.bdj.2008.613 }
\end{array}
$$

\section{RARE NEOPLASMS}

Sir, a 42-year-old Caucasian male was referred urgently by his GDP to the Department of Oral \& Maxillofacial Surgery. He presented with a ten month history of blocked right nostril, slight epistaxis, pain and tenderness of the teeth in the upper right maxilla. He had previously consulted his GMP who diagnosed sinusitis and a course of antibiotics was prescribed. There was no improvement in his symptoms. The patient then visited his GDP who commenced root canal treatment of the 16 as this tooth was suspected of being responsible for the symptoms. Again, there was no improvement in his symptoms. This led the GDP to take an OPG which showed radio opacity of the right maxillary antrum.

Clinical examination revealed no paraesthesia of the right cheek, no visual problems and no cervical lymphadenopathy. Intraorally the 16 was tender to palpation and the 17 was grade I mobile but not TTP. A CT scan of the sinuses showed soft tissue opacity based within the right maxillary antrum with marked bony remodelling evident and deviation of the nasal septum to the right (Fig. 1). Bony destruction of the medial wall of the maxillary antrum was noted.

An incisional biopsy of the right maxillary antrum under general anaesthetic

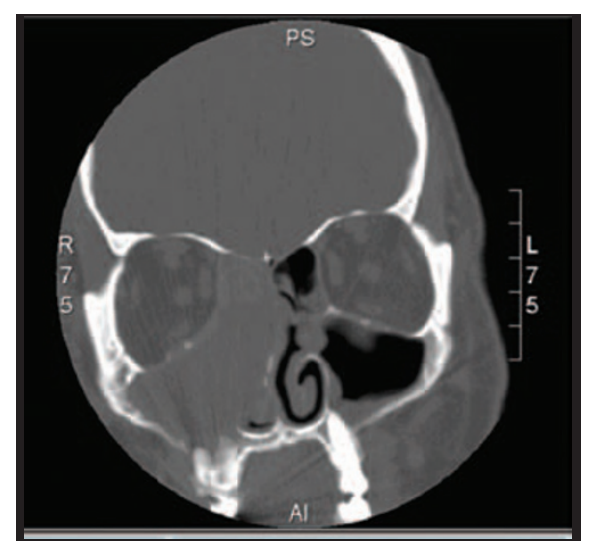

Fig. 1 CT scan of the sinuses 
via a Caldwell-luc approach revealed a neuroendocrine carcinoma. The patient underwent a hemi maxillectomy and is currently doing well. Neuroendocrine carcinoma of the paranasal sinuses are extremely rare neoplasms. This tumour was first reported in this site in 1965, and since then there have been only 61 documented cases in the literature. ${ }^{1}$

The case shows a pattern of tumour presentation that was initially clinically interpreted to indicate an odontogenic infection. It is important that GDPs obtain an accurate history and carry out a thorough examination before making a diagnosis. The GDP in this case has shown that if there is no response or improvement of the patient's symptoms following dental treatment it is imperative that clinicians think again and consider pathology arising from other anatomical structures present in the head and neck.

The patient's GDP is to be congratulated in the management of this case.

\section{A. Patel \\ London}

1. Georgiou A F, Walker D M, Collins A P et al. Primary small cell undifferentiated (neuroendocrine) carcinoma of the maxillary sins. Oral Surg Oral Med Oral Pathol Oral Radiol Endod 2004; 98: 572-578

DOI: 10.1038/sj.bdj.2008.614

\section{FORMOCRESOL REVISITED}

Sir, I am writing in response to B. B. Lewis' letter regarding formocresol ( $B D J$ 2008; 204: 477). Dr Lewis purports to have made a strong case to eliminate formocresol from paediatric dentistry. ${ }^{1}$ Although Dr Lewis claims that his concern is 'for your readership, well-meaning clinicians who might be confused by position papers that distort the overwhelming body of evidence that cite the genotoxicity, mutagenicity, carcinogenicity, and toxicity of formaldehyde', his argument in his letter is sadly outof-date and unscientific.

He cites no evidence to support his case. On the contrary, I refer readers to my recent papers on formocresol ${ }^{2,3}$ which present an up-to-date interpretation of the scientific evidence regarding formaldehyde. The research on formaldehyde from 30 years ago that $\mathrm{Dr}$ Lewis blandly refers to has now, for the most part, been discredited or updated primarily because newer and more rigorous methodology has been used to investigate formaldehyde. Furthermore, Dr Lewis' statement that 'systemic distribution [of formaldehyde] after formocresol pulpotomy is irrefutable' is absolute nonsense based on current scientific evidence.

Dr Lewis claims to be approaching this issue scientifically but his apparent ignorance of recent literature about formaldehyde metabolism is shocking. While I encourage readers to look for a biological alternative to formocresol, I urge those who are considering abandoning formocresol to do so for scientific reasons and not for dogmatic, fear-mongering reasons.

A. Milnes

British Columbia

1. Lewis B. Formaldehyde in dentistry: a review for the millennium. J Clin Pediatr Dent 1998; 22: 167-177.

2. Milnes A R. Persuasive evidence that formocresol use in pediatric dentistry is safe. $J$ Can Dent Assoc 2006; 72: 247-248.

3. Milnes A. Is formocresol obsolete? A fresh look at the evidence concerning safety issues. In press to be published concurrently in Pediatr Dentistry 2008; July 30: and J Endod 2008; 34: 7 S.

DOI: 10.1038/sj.bdj.2008.615

\section{ANOMALOUS}

Sir, I write in response to the published letter from Professors Strunin and Wildsmith regarding conscious sedation ( $B D J$ 2008; 204: 541-542).

The situation in Scotland is different from in England. Professor Wildsmith in his position as Chairman of The Royal College of Anaesthetists Board in Scotland recommended in March 2001 to the then deputy CDO that only single drug sedation should be used in the general dental practice setting whereas in England multiple drug sedation is still allowed under the GDS regulations.

The Standing Committee on Sedation for Dentistry of which Professor Wildsmith was a member reinforced this guidance.

It seems to me to be anomalous that safety guidelines, of which The Royal College of Anaesthetists have been instrumental in formulating, should not be consistent throughout the entire United Kingdom.

\section{PROFESSIONAL VIGILANCE}

Sir, the report on the recent study day at the Royal College of Surgeons, London in the news section of the recent $B D J$ $(2008$; 204: 361) highlights the importance of vigilance on the part of dental professionals to this important aspect of total patient care.

Only a few days ago a single mother brought her child aged just 14 years for a consultation with me. The child seemed apathetic and withdrawn and her mother explained that the child was about five months pregnant. I gently probed the mother who seemed furtive. I explained that sexual intercourse with a child is a criminal offence and that I might have to report the matter at which she gave me a full explanation which included the involvement of Social Services and other agencies. I told her that I would record details of the interview in the child's dental records and take no further action.

I have over the years had to report to the authorities a few cases where circumstances have been suspicious. DCPs often see and hear things in the waiting room that we do not pick up on. Dealing with such matters requires great diplomacy and bravery but what gave me the courage to take this action was the memory of an account some years ago of a mother of a child similarly aged, who after the termination of a pregnancy, told me that her husband, the child's father, had received a custodial sentence for the offence.

In a year of general practice most practitioners will see children who have had dental injuries and though child abuse is fortunately rare, dental injuries are only one manifestation of child neglect. For those who would shrink away from involvement the option has been removed by the need to comply with Core Standard 2 of Clinical Governance that refers to child protection. All Primary Care Trusts have policies in place and information on referral systems to which dental practices have access. Moreover, is it not a professional obligation that became ours when we entered the profession to protect children and vulnerable adults?

M. J. T. de Mendonca Brighton DOI: 10.1038/sj.bdj.2008.617 